\title{
Ruptured aneurysm of Sylvian Artery in a Neonate, 9 weeks old - case report
}

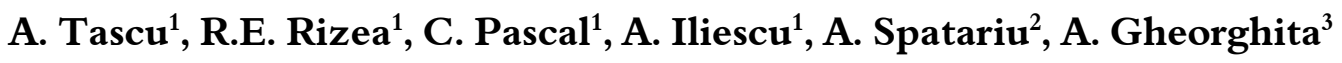 \\ ${ }^{1} 1^{\text {st }}$ Neurosurgery Clinic, ${ }^{2} 3^{\text {rd }}$ Neurosurgery Clinic, ${ }^{3}$ Neuroasthesiology Department \\ Emergency Hospital "Bagdasar-Arseni”, Bucharest, Romania
}

\section{Introduction}

In child population, intracranial aneurysm has a very low incidence, representing less than $5 \%$ of all intracranial aneurysms (1-5). The clinical manifestation is usually untypical, including greater variation in anatomic distribution, male predominance, and higher incidences of occurrence in the posterior circulation and of giant aneurysms (6-14). Approximately $0.5 \%-4.6 \%$ of intracranial aneurysms occur in patients 18 years of age or younger.(7, 15-20) In a well-known study reported in 1966, only 41 of 6368 ruptured aneurysms were found in patients younger than 19 years and only 1 intracranial aneurysm occurred in a patient who was under 4 years of age.(21) Moreover, although some risk factors for the formation of intracranial aneurysms have been identified in adults (family history, age older than 50 years, smoking, cocaine use, and hypertension), in childhood most of these risk factors do not exist.(22-25) Not only do discrepancies exist in the clinical description of this rare entity but also in reports regarding its outcome after treatment. Good outcomes have been reported to range from $40 \%$ to $95 \%$ in the surgical literature. $(7,11,13,26-$ 30). Agid et al. (31) reported a series covering 12 years (1992-2004) that included 9 ruptured pediatric aneurysms. A Johns Hopkins group reported their 14- year experience (1991-2004) in treating 11 children with SAH by means of surgical clipping (29).

We report and describe a successfully clipped ruptured aneurysm of sylvian artery in a neonate, which was diagnosed using magnetic resonance (MR) imaging with Angio-MR and confirmed at subsequent surgery. In this case, deposition of thrombosis was noted on histological examination of the wall at the parent arteryaneurysm junction.

\section{Case Presentation}

The patient was a 9-weeks-old boy born by normal vaginal delivery after an uncomplicated, 40-week pregnancy. Her birth weight was $2600 \mathrm{gm}$. There was no history of infectious disease or head injury. On the evening of December 21, 2012, he suddenly vomited and became lethargic after a feeding of milk. She was admitted to the Department of Neurosurgical Pediatrics of "Bagdasar-Arseni" Emergency Hospital on the same evening. On admission, he was neither pale nor febrile.

Her head circumference was $34 \mathrm{~cm}$ and there was bulging of the anterior fontanel. $\mathrm{He}$ responded poorly to stimuli but exhibited normal motor function in all four extremities. The peripheral blood hemoglobin concentration was $8.8 \mathrm{gm} / \mathrm{dl}$ and hematocrit was $32.3 \%$. The peripheral 
white cell count was $7300 / \mathrm{mm} 3$. Blood chemistries were normal.

Soon after admission he suddenly had a left hemiconvulsion and gradually became more non responsive. Emergency CT cerebral disclosed a large hematoma with perifocal edema in the right frontotemporooccipital region (Figure 1), which suggested that the hematoma resulted from rupture of an arterio-venous malformation or an aneurysm rather than from vitamin $\mathrm{K}$ deficiency.

Because the day of admission - Friday evening - the DSA (Digital Substraction Angiography) was not avaible more dates was necessary and we decided Angio-MR, the only solution at the moment. The Angio-MR not showed an aneurysm, presumably the right sylvian artery, but the cerebral MRI show a massive right cerebral haematoma (Figure 2). There was no arteriovenous fistula or malformation. Examinations for aortal coarctation and polycystic kidney were negative (Electrocardiogram, Chest X-ray and Abdominal Ecography).

In the same night on December 21, 2012 after the onset of symptoms, a right frontotemporoparietal craniotomy was performed. A right frontotemporoparietal cerebral hematoma is evacuated. Intraoperative, incidental discovery, is an aneurysm with thrombosis from one branch of the right sylvian artery, which measured $25 \mathrm{~mm}$ in its largest diameter, located in the right Sylvian fissure. So the saccular aneurysmal neck could be identified and and a "Yasargil" type clip was used for excluding malformation from circulation.

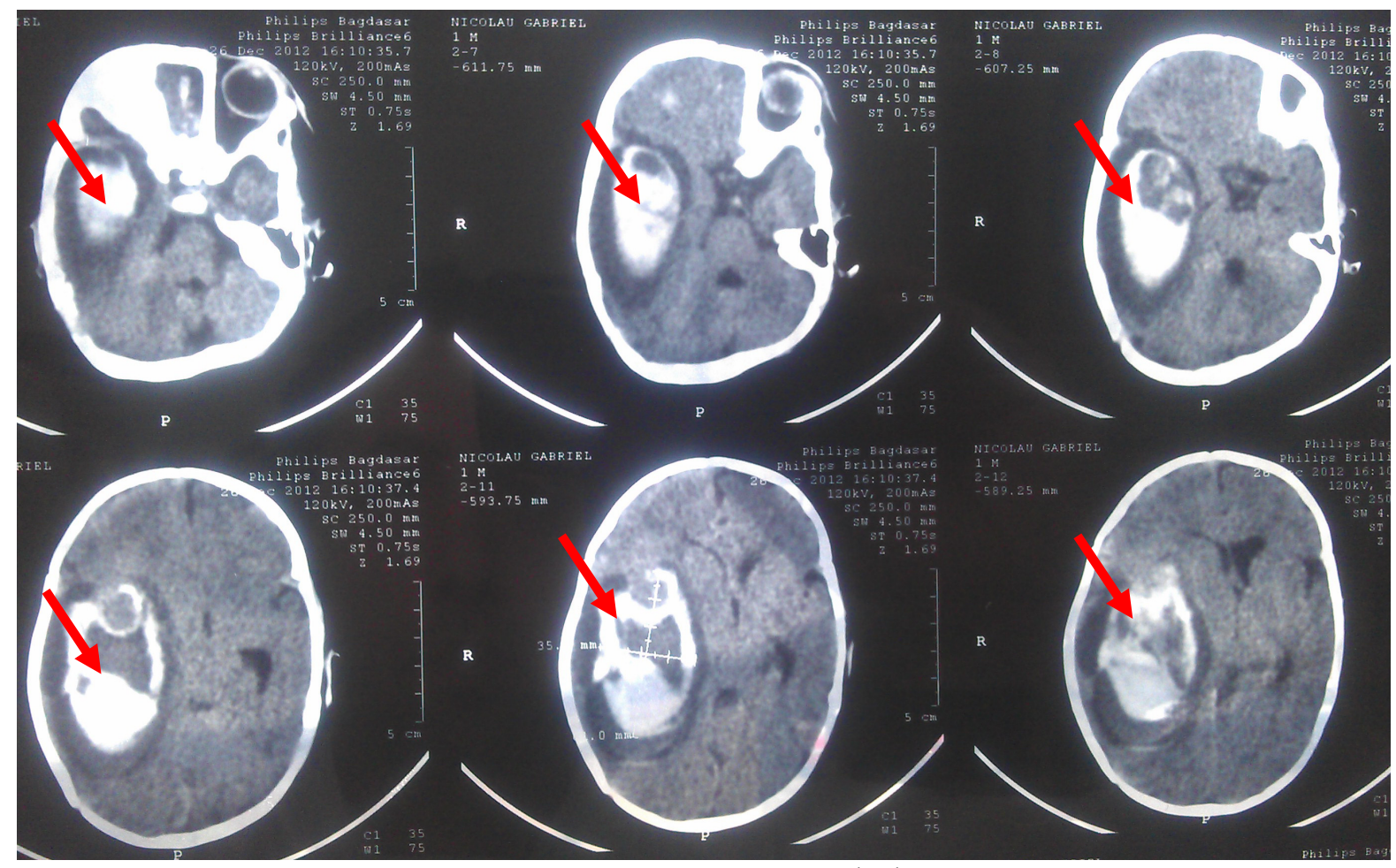

Figure 1 Preoperative CT cerebral 


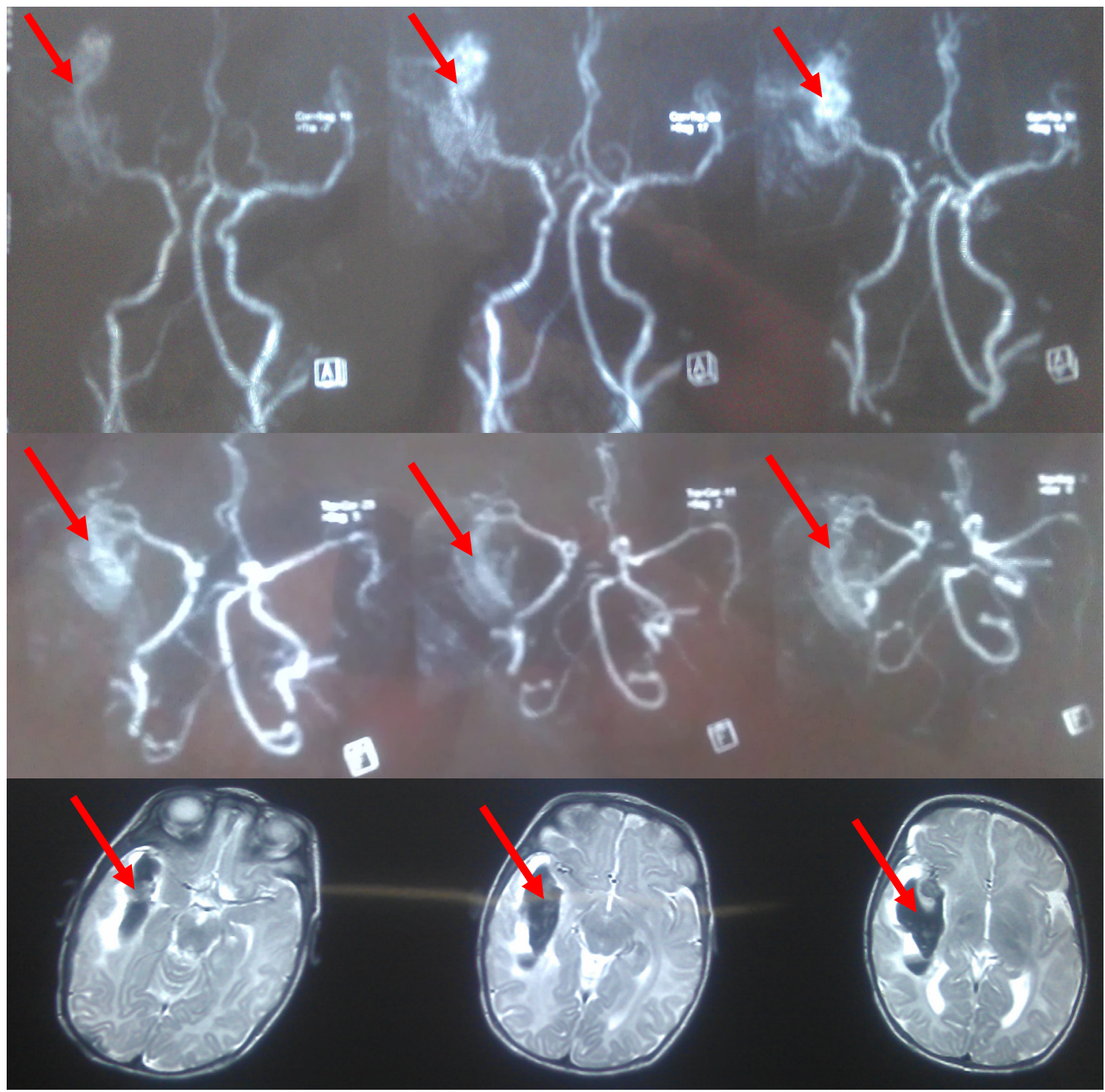

Figure 2 Preoperative MRI and Angio-MR

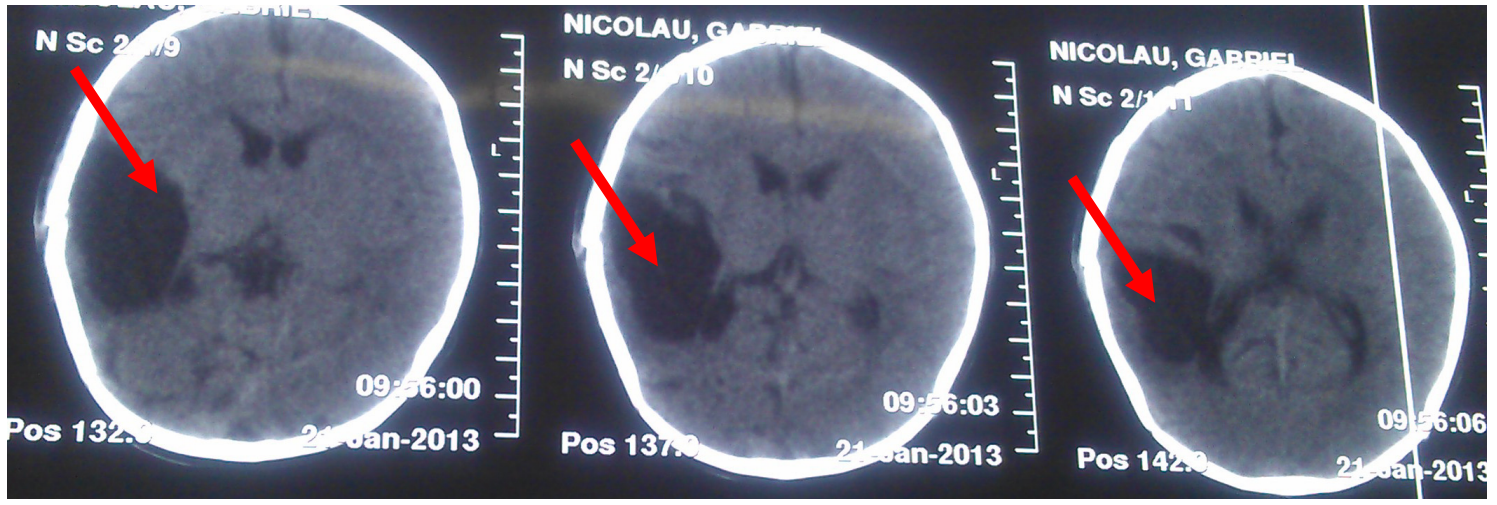

Figure 3 Postoperative CT cerebral 
The aneurysmal dome was excised and no blood or fluid could be aspirated upon puncture of the aneurysmal dome. The piece of dome together with the intraluminal thrombus was histologically examined.

Histological examination of the specimen revealed intraluminal granulation tissue with thrombosis and no elastic fibers in the aneurysm.

The postoperative course was uneventful, and the postoperative CT cerebral was without bleeding (Figure 3). The posthaemorrhagic anemia was postoperative corrected. He was discharged 8 days after surgery without neurological deficits. At 1 month after surgery, he continues to do well with normal psychomotor development.

\section{Discussion}

Intracranial aneurysms are very uncommon in infants and young children.

The first report of aneurysmal surgery on an infant was by Jones and Shearburn (32) in 1961. Since then, the results of many such operations have been reported, (33-36) and most cases involved aneurysms of the MCA. Whereas the prognosis for infants with ruptured posterior fossa aneurysms is poor, the outcome of surgery for MCA aneurysms tends to be good. The more favorable outcome with aneurysms of the MCA in infants has been attributed to the formation of intracerebral hematomas at peripheral sites, (34) the rarity of vasospasm, (37) and the good functional compensation of the young brain. (38)

In literature data Schimauchi et al presented in 1989 the youngest patient with intracranial aneurysm who have 19 days old at presentation (39). In 1995 Hosotani et al presented a case of intracranial aneurysm at an infant male 34 days old (40). Hirata and coworkers (34) found 49 patients under 2 years of age. Lipper et al (41) and Kunimine et al.(35) reviewed 19 and 31 cases, respectively, involving patients in the first year of life.

All literature data concluded similarly that aneurysms in infants have the following characteristics in comparison with those in adults: 1) there are higher incidences of aneurysms of the MCA and its branches and of the vertebrobasilar system; 2) the aneurysms tend to be larger; 3 ) there is a higher incidence of symptoms due to mass effect; and 4) the prognosis is better, even if the initial neurological status is poor, especially in cases of MCA aneurysms, because the infantile central nervous system has greater capacity for recovery than in adults; 5) the mortality of patients not treated surgically due to poor initial neurological status is $100 \%$. Recent improvements in surgical techniques and neuro-anesthesiology may allow more aggressive treatment of such aneurysms in neonates.

As in our case, MR imaging and Angio MR not demonstrate the aneurysmal location, because the DSA was not avaible at admission in hospital. MR imaging and DSA will be increasingly important in the diagnosis and treatment of pediatric aneurysms and may lead to increased success in treating these aneurysms. Improvement of the prognosis is expected for patients with neonatal ruptured aneurysms in the future.

The etiology of aneurysms in infants is controversial. The major argument is whether aneurysms are congenital or acquired. Forbus (42) proposed that a 
congenital medial defect of the arterial wall may be the primary

factor in the formation of saccular aneurysms. Kaplan and Hahn (43) classified infantile aneurysms by etiology as follows: one-third traumatic, one-third mycotic, and one-third congenital.

Bremer (44) favored another theory of congenital formation: during fetal development of the cerebral arterial system, the proximal portion of the cerebral arterial plexuses may enlarge, while the distal segments degenerate and shrink, thus producing an aneurysmal sac. On the other hand, Stehbens (45) postulated that socalled saccular aneurysms derive from degenerative changes at the arterial fork, rejecting the concept of a congenital origin. $\mathrm{He}$ asserted that the aneurysms in infants that have been reported to date were not truly congenital

In our case the aneurysm was saccular, and there was deposition of thrombus. Histological examination of the specimen revealed intraluminal granulation tissue with thrombosis and no elastic fibers in the aneurysmal. Another type, fusiform aneurysms, are frequently associated with atherosclerotic dilatation, and calcification is often seen in the aneurysmal wall.

\section{Conclusions}

In child population, intracranial aneurysm has a very low incidence, representing less than $5 \%$ of all intracranial aneurysms. The clinical manifestation is usually untypical. The etiology of aneurysms in infants is controversial. The treatment of choice is the surgery with clipping. The aneurysms in infants tend to be larger. The prognosis is better, but the mortality of patients not treated surgically tend to $100 \%$.

\section{References}

1. Locksley HB: Natural history of subarachnoid hemorrhage, intracranial aneurysms and arteriovenous malformations. Based on 6368 cases in the cooperative study. J Neurosurg 25: 219-239, 1966.

2. Patel AN, Richardson AE: Ruptured intracranial aneurysms in the first two decades of life. A study of 58 patients. J Neurosurg 35: 571-576, 1971.

3. Heiskanen $\mathrm{O}$ : Ruptured intracranial arterial aneurysms of children and adolescents. Surgical and total management results. Childs Nerv Syst 5: 66-70, 1989.

4. Laughlin S, TerBrugge $\mathrm{KG}$ et $\mathrm{Al}$ : Endovascular management of paediatric intracranial aneurysms. Interventional Neuroradiology 3: 205-214, 1997.

5. Lasjaunias PL, Campi A et Al: Aneurysmal disease in children: review of 20 cases with intracranial arterial localisations. Interventional Neuroradiology 3: 215-229, 1997.

6. Allison JW, Davis PC, Sato Y, James CA, Haque SS, Angtuaco EJC, Glasier CM (1998) Intracranial aneurysms in infants and children. Pediatr Radiol 28:223-229.

7. Meyer FB, Sundt TM Jr, Fode NC, Morgan MK, Forbes GS, Mellnger JF (1989) Cerebral aneurysms in childhood and adolescence. J Neurosurg 70:420-425.

8. Ferrante L, Fortuna A, Celli P, Santoro A, Fraiolo B (1988) Intracranial arterial aneurysms in early children. Surg Neurol 29:39-56.

9. Humphreys RP (1989) Intracranial arterial aneurysms. In: Edwards MSB, Hoffman HJ (eds) Cerebral vascular disease in children and adolescents. Williams \& Wilkins, Baltimore, pp 247-254.

10. Hacker RJ (1982) Intracranial aneurysms of childhood: a statistical analysis of 500 cases from the world literature. Neurosurgery 10:775 (Abstract).

11. Herman JM, Rekate HL, Spetzler RF (1991) Pediatric intracranial aneurysms: simple and complex cases. Pediatr Neurosurg 17:66-73.

12. Proust F, Toussaint P, Garnieri J, Hannequin D, Legars D, Houtteville JP, Freger P (2001) Pediatric cerebral aneurysms. J Neurosurg 94:733-739.

13. Pasqualim A, Mazaa C, Cavazzani P, Scineza R, Dapian R (1986) Intracranial aneurysms and subarachnoid hemorrhage in children and adolescents. Child Nerv Syst 2:185-190.

14. Zhao J, Sun H, Wang S (2006) Neuroendoscopeassisted minimally invasive microsurgery for clipping intracranial aneurysms. Min Inv Neurosurg 49:335-341 15. Gerosa M, Licata C, Fiore DL, et al. Intracranial aneurysms of childhood. Childs Brain 1980;6:295-302. 16. Ostergaard JR, Voldby B. Intracranial arterial aneurysms in children and adolescents. J Neurosurg 1983;58:832-37.

17. Patel AN, Richardson AE. Ruptured intracranial 
aneurysms in the first two decades of life: a study of 58 patients. J Neurosurg 1971;35:571-76.

18. Roche JL, Choux M, Czorny A, et al. Intracranial arterial aneurysm in children: a cooperative study apropos of 43 cases (in French). Neurochirurgie 1988; $34: 243-51$.

19. Sedzimir CB, Robinson J. Intracranial hemorrhage in children and adolescents. J Neurosurg 1973;38:26981.

20. Pasqualin A, Mazza C, Cavazzani P, et al. Intracranial aneurysms and subarachnoid hemorrhage in children and adolescents. Childs Nerv Syst 1986;2: 185-90.

21. Locksley HB, Sahs AL, Sandler R. Report on the cooperative study of intracranial aneurysms and subarachnoid hemorrhage. 3. Subarachnoid hemorrhage unrelated to intracranial aneurysm and A-V malformation: a study of associated diseases and prognosis. J Neurosurg 1966;24:1034-56.

22. Juvela S. Risk factors for multiple intracranial aneurysms. Stroke 2000;31:392-97.

23. Juvela S. Natural history of unruptured intracranial aneurysms: risks for aneurysm formation, growth, and rupture. Acta Neurochir Suppl 2002;82:27-30.

24. King JT Jr. Epidemiology of aneurysmal subarachnoid hemorrhage. Neuroimaging Clin N Am 1997;7:659-68.

25. Rinkel GJ, Djibuti M, Algra A, et al. Prevalence and risk of rupture of intracranial aneurysms: a systematic review. Stroke 1998;29:251-56.

26. Amacher AL, Drake CG, Ferguson GG. Posterior circulation aneurysms in young people. Neurosurgery 1981;8:315-20.

27. Heiskanen O, Vilkki J. Intracranial arterial aneurysms in children and adolescents. Acta Neurochir (Wien) 1981;59:55-63.

28. Aryan HE, Giannotta SL, Fukushima T, et al. Aneurysms in children: review of 15 years experience. J Clin Neurosci 2006;13:188-92.

29. Huang J, McGirt MJ, Gailloud P, et al. Intracranial aneurysms in the pediatric population: case series and literature review. Surg Neurol 2005;63:424 -32, discussion 432-33.

30. Sanai N, Quinones-Hinojosa A, Gupta NM, et al. Pediatric intracranial aneurysms: durability of treatment following microsurgical and endovascular management. J Neurosurg 2006; 104:82-89.

31. Agid R, Souza MP, Reintamm G, Armstrong D, Dirks P, TerBrugge KG: The role of endovascular treatment for pediatric aneurysms. Childs Nerv Syst 21:1030-1036, 2005.

32. Jones RK, Shearburn EW: Intracranial aneurysm in a four-week-old infant. Diagnosis by angiography and successful operation. J Neurosurg 18: 122-124, 1961.

33. Grode ML, Saunders M, Carton CA: Subarachnoid hemorrhage secondary to ruptured aneurysms in in fants. Report of two cases. JNeurosurg 49: 898-902, 1978.

34. Hirata K, Yamashita T, Ishiwata Y, Yamaguchi K, Kuwabara T: A case report of the intracranial aneurysm in an infant. Shoni No Noshinkei 8: 1-7, 1983 (in Japanese).

35. Kunimine $H$, Inoue $H$, Isobe I, Nukui $H$ : In tracranial aneurysm in an infant. Report of a case and review of 31 cases in the literature. No Shinkei Geka 11: 531-538, 1983 (in Japanese).

36. Ventureyra ECG, Choo SH, Benoit BG: Super giant globoid intracranial aneurysm in an infant. Case report. J Neurosurg 53: 411-416, 1980.

37. Matson DD: Intracranial arterial aneurysms in childhood. J Neurosurg 23: 578-583, 1965.

38. Orozco M, Trigueros F, Quintana F, Dierssen G: In tracranial aneurysms in early childhood. Surg Neurol 9: 247-252, 1978

39. Masaki Shimauchi, Yuzo Yamakawa, Nobuhiko Maruoka, Kazuaki Miyake: Ruptured Intracranial Aneurysm in a 19-day-old Infant-Case Report. Neurol Med Chir (Tokyo) 29, 1047-1050, 1989.

40. Kazuo Hosotani, Yasuhiko Tokuriki, Yoshihiro Takebe, Kenji Kawaguchi, Atsushi Tsuji, Toshihiko Kubota: Ruptured Aneurysm of the Distal Posterior Inferior Cerebellar Artery in a Neonate-Case Report. Neurol Med Chir (Tokyo) 35, 892-895, 1995.

41. Lipper S, Morgan D, Krigman MR, Staab EV: Con genital saccular aneurysm in a 19-day-old neonate. Case report and review of the literature. Surg Neurol 10: 161-165, 1978.

42. Forbus WD: On the origin of miliary aneurysms of the superficial cerebral arteries. Bull Hopkins Hosp 47: 239-284, 1930.

43. Kaplan PA, Hahn FJ: Aneurysms of the posterior cerebral artery in children. AJNR 5: 771-774, 1984

44. Bremer JL: Congenital aneurysms of the cerebral arteries. An embryologic study. Arch Path (Chicago) 35: 819-831, 1943.

45. Stehbens WE: Pathology of the Cerebral Blood Vessels. St. Louis, CV Mosby, 1972, pp 351-470. 